\title{
MicroRNA expression profiling in patients with hepatocellular carcinoma of familial aggregation and hepatitis $B$ virus infection
}

\author{
ER-LEI ZHANG, JIN GU, ZUN-YI ZHANG, KE-SHUAI DONG, BIN-YONG LIANG and ZHI-YONG HUANG \\ Hepatic Surgery Center, Tongji Hospital, Tongji Medical College, Huazhong University \\ of Science and Technology, Wuhan, Hubei 430030, P.R. China
}

Received September 18, 2015; Accepted February 23, 2017

DOI: $10.3892 / \mathrm{ol} .2017 .6178$

\begin{abstract}
Numerous studies have suggested that microRNAs (miRNAs) potently affect hepatocarcinogenesis. However, the miRNA expression profiling in patients with hepatocellular carcinoma (HCC) of familial aggregation and hepatitis $B$ virus (HBV) infection has not been elucidated. In the present study, the plasma miRNA expression profiles of 3 patients with HCC with familial aggregation of HCC and HBV infection and 1 healthy volunteer were examined by microarray analysis, in order to identify relevant miRNAs involved in the pathogenesis of HCC with familial aggregation and HBV infection. The results indicated that 26 miRNAs exhibited a $\geq 20$-fold increase or decrease in the plasma of patients with HCC, compared with the healthy control (24 upregulated and 2 downregulated). Among these altered miRNAs, 15 of them have been reported in HCC. The other 11 miRNAs have never been reported in HCC. These differentially-expressed miRNAs may be potential molecular markers for $\mathrm{HCC}$ pathogenesis and development.
\end{abstract}

\section{Introduction}

Hepatocellular carcinoma (HCC) remains one of the most prevalent malignant diseases in the world (1). Chronic infection with the hepatitis B virus (HBV) is the most important risk factor for HCC, accounting for $55 \%$ of global incidences and $>80 \%$ of cases in Asia and sub-Saharan Africa (2). Patients infected with $\mathrm{HBV}$ are known to be at an increased risk of developing $\mathrm{HCC}$ over their lifetime (3-5). Previous studies have reported familial aggregation of HCC $(6,7)$, and previous meta-analyses have indicated that family history of HCC increases the risk of HCC in patients with viral hepatitis, independently of hepatitis (8). A previous study examined the effect of a family history of $\mathrm{HCC}$ on

Correspondence to: Dr Zhi-Yong Huang, Hepatic Surgical Center, Tongji Hospital, Tongji Medical College, Huazhong University of Science and Technology, 1095 Jie Fang Da Dao, Wuhan, Hubei 430030, P.R. China

E-mail: zyhuang@medmail.com.cn

Key words: microRNA, microarray profiling, hepatocellular carcinoma, hepatitis B virus, familial aggregation the incidence of $\mathrm{HCC}$ in the entire population who were screened for HBV seromarkers, and elucidated that family history of $\mathrm{HCC}$ multiplied the risk of HCC at each stage of HBV infection (7). Although numerous molecular studies have revealed that the HBV-encoded X (HBx) protein performs a critical role in hepatocarcinogenesis in patients with HBV-associated HCC (9-12), the mechanisms underlying familial clustering-associated carcinogenesis remain to be fully elucidated.

MicroRNAs (miRNAs/miRs) comprise a class of highly-conserved noncoding RNAs of 22 nucleotides in length (13). Mature miRNAs may interact with the 3'-untranslated regions (UTRs) of target mRNAs to form RNA-induced silencing complexes, resulting in the inhibition of translation or mRNA cleavage (14). Previous studies have revealed that miRNAs may regulate gene expression at the posttranscriptional level and performs a role in regulating epigenetic machinery, including DNA methylation and histone modification (15-18). Since miRNAs perform important roles in various pivotal biological processes, dysregulated miRNA expression has been implicated in a variety of human diseases, including chronic HBV infection and hepatocarcinogenesis (19). An increasing amount of evidence has indicated that dysregulation of miRNAs has important roles in HBV infection and HBV-associated HCC $(9,20-22)$. Numerous studies have demonstrated that the HBx protein is associated with the regulation of miRNAs, which affects basic tumor processes, including cellular proliferation, differentiation and metastasis (12,23-27). In addition, a family history of HCC increases the risk of HCC, even following adjustment for other risk factors, and in patients without hepatitis serum markers (28). However, little is known regarding the association between miRNAs and family aggregation of $\mathrm{HCC}$ in patients with HBV infection.

In the present study, microarray analysis was performed to study the miRNA profile in the plasma of patients with HCC with familial aggregation of HCC and HBV infection, compared with the healthy control. The present study may help improve understanding of the key roles of miRNAs in the progression of HCC, and pave the way to future studies on the molecular mechanism of hepatocarcinogenesis.

\section{Materials and methods}

Patients and samples. A total of 3 patients with HCC with a history of familial aggregation of HCC and HBV infection 
Table I. Baseline information of 3 patients with $\mathrm{HCC}$ and 1 volunteer.

\begin{tabular}{lccllll}
\hline Patient & Sex & Age, years & Diagnosis & Edmondson-steiner grade & Family history of HCC & Sampling date \\
\hline 1 & F & 42 & HBV/HCC & II & One sister and one brother & $2011-12-24$ \\
2 & M & 43 & HBV/HCC & I & Two brothers & $2012-01-28$ \\
3 & M & 38 & HBV/HCC & II & Father and one brother & 2012-03-17 \\
Control & M & 38 & Healthy & - & None & $2012-03-18$
\end{tabular}

HCC, hepatocellular carcinoma; HBV, hepatitis B virus; F, female; M, male.

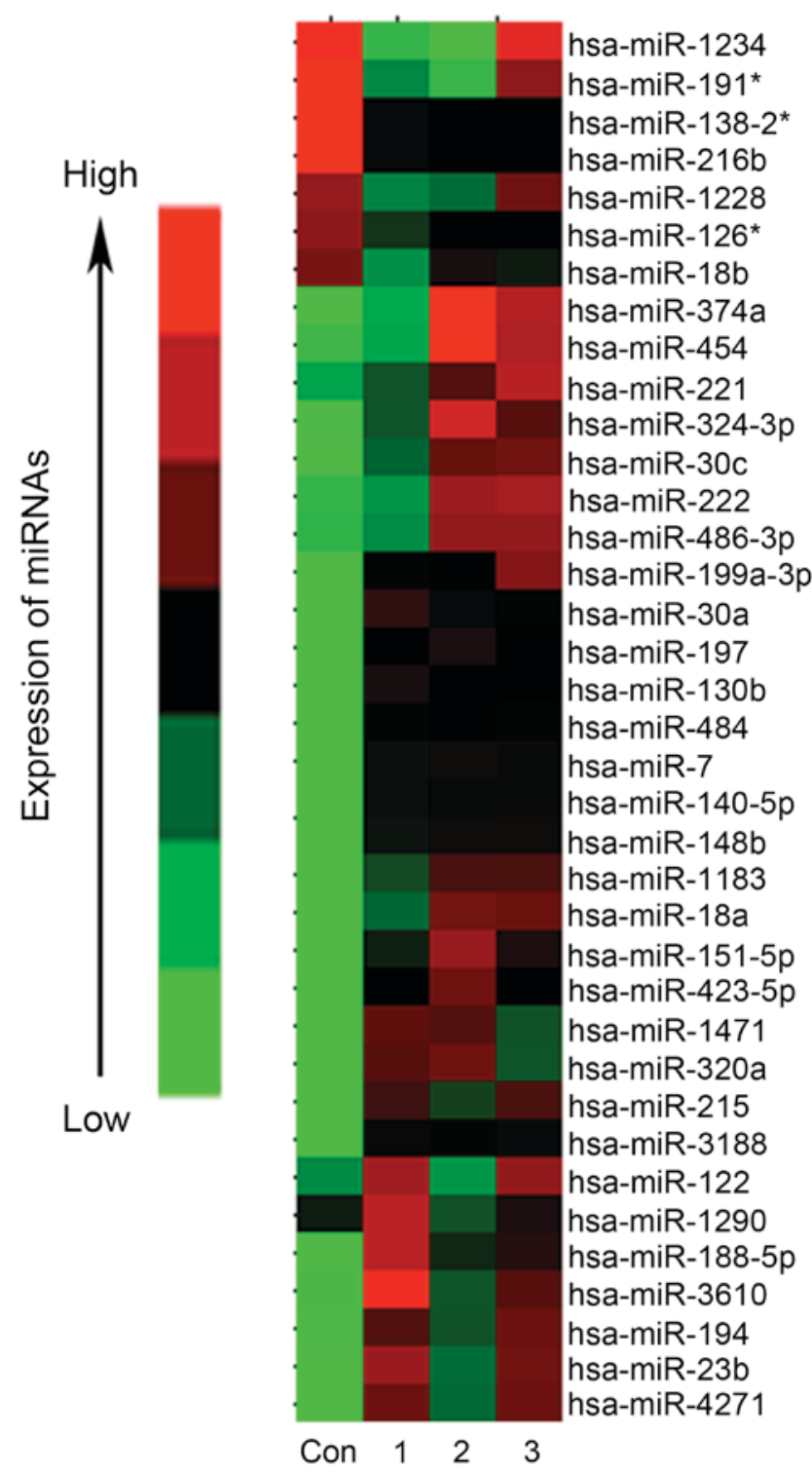

Figure 1. Heatmap of differentially-expressed miRNAs in the plasma of a healthy control and 3 patients with HCC with family history of HCC and hepatitis $B$ virus infection using microarray analysis. miRNA/miR, microRNA; HCC, hepatocellular carcinoma; hsa, Homo sapiens.

underwent liver resection at the Hepatic Surgery Center, Tongji Hospital, Tongji Medical College, Huazhonog University of Science and Technology (Wuhan, China) between December 2011 and March 2012. Blood samples were obtained from these 3 patients prior to liver resection. HCC was diagnosed based on cytohistological evidence from resected specimens. These patients were not treated with any radiochemotherapy prior to blood drawing. Blood collected from a healthy volunteer was used as a control. The baseline information of all enrolled subjects is presented in Table I. Written consent for sample collection was obtained from all the patients, and the protocol was approved by the Institutional Research Ethics Committee of Tongji Hospital, Tongji Medical College, Huazhong University of Science and Technology.

Familial aggregation of HCC is defined as having a first degree relative (including parents, siblings and children) with HCC (7). The diagnosis of familial aggregation of HCC of these 3 patients was confirmed with the help of a standardized questionnaire that was given to all patients at the baseline visit. Other family members also received liver resection or medical treatment at Tongji Hospital with the diagnosis of HCC. Their blood samples are no longer available as they have passed away.

miRNA microarray analysis. Plasma samples were acquired by high-speed centrifugation $\left(12,000 \mathrm{x} \mathrm{g}\right.$ at $4^{\circ} \mathrm{C}$ for $\left.10 \mathrm{~min}\right)$ and stored at $-80^{\circ} \mathrm{C}$. Agilent human miRNA V16.0 from Agilent Technologies (Santa Clara, CA, USA) was used to identify differentiated miRNAs between familial patients with $\mathrm{HCC}$ with HBV infection and the healthy volunteer. All protocols were performed by the professional Shanghai Biological Corporation (Shanghai, China).

Data analysis. According to the results of microarray analysis, the miRNAs that exhibited $\geq 20$-fold increase or decrease in the plasma of patients with HCC compared with the healthy control were selected. To evaluate the list of differentially-expressed miRNAs in the context of the current literature, the names of these differentially-expressed miRNAs were used as a keyword for online searches and detailed information was extracted. The following databases were utilized: PubMed (https://www.ncbi.nlm.nih.gov/pubmed/), Web of Science (http://www.webofknowledge.com/) and Google Scholar (http://scholar.google.com) search.

\section{Results}

Microarray results of the differentially-expressed miRNAs in the plasma of patients with HCC. Microarray results identified 37 miRNAs with a significant difference in expression between the patients with HCC and the healthy control, including 30 upregulated and 7 downregulated (Fig. 1) (27). Among 
Table II. miRNAs have been reported in HCC, which exhibited at least a 20-fold increase or decrease in plasma expression of patients with HCC compared with the healthy control.

\begin{tabular}{|c|c|c|c|c|c|c|}
\hline miRNA name & Sequence & Fold-change & Targets & Published year & Chr & HBx regulation \\
\hline hsa-miR-215 & GTCTGTCAATTCATAGGTCAT & 277.3 & PTPRT & 2014 & $\operatorname{chr} 1$ & Yes \\
\hline hsa-miR-3188 & CCCCGTATCCGCA & 124.5 & mTOR & 2016 & chr19 & No \\
\hline hsa-miR-23b & GGTAATCCCTGGCAATG & 102.9 & c-Met & 2009 & chr9 & No \\
\hline hsa-miR-18a & CTATCTGCACTAGATGCA & 97.3 & $\mathrm{ER}-\alpha$ & 2009 & chr13 & Yes/no \\
\hline hsa-miR-320a & TCGCCCTCTCAAC & 88.3 & GNAI1 & 2012 & chr8 & No \\
\hline hsa-miR-199a-3p & TAACCAATGTGCAGACTACT & 63.7 & $\mathrm{mTOR} / \mathrm{c}-\mathrm{Met}$ & 2010 & $\operatorname{chr} 1$ & No \\
\hline hsa-miR-151-5p & ACTAGACTGTGAGCTCC & 61.2 & RhoGDIA & 2010 & $\operatorname{chr} 8$ & No \\
\hline hsa-miR-140-5p & CTACCATAGGGTAAAACCACT & 38.2 & TGF- $\beta$ & 2013 & $\operatorname{chr} 16$ & No \\
\hline hsa-miR-130b & ATGCCCTTTCATCATTGC & 34.9 & PPAR- $\gamma$ & 2014 & $\operatorname{chr} 22$ & No \\
\hline hsa-miR-197 & GCTGGGTGGAGAAGGTG & 33.8 & CD82 & 2014 & chr1 & No \\
\hline hsa-miR-148b & ACAAAGTTCTGTGATGCAC & 33.4 & NA & 2014 & $\operatorname{chr} 12$ & No \\
\hline hsa-miR-30a & CTTCCAGTCGAGGATG & 31.1 & SNAI1 & 2014 & chr6 & No \\
\hline hsa-miR-7 & ACAACAAAATCACTAGTCTTCC & 24.5 & CCNE1 & 2013 & chr9 & Yes \\
\hline hsa-miR-30c & GCTGAGAGTGTAGGATGT & 24.4 & NA & 2014 & $\operatorname{chr} 1$ & No \\
\hline hsa-miR-194 & TCCACATGGAGTTGCT & 22.2 & NA & 2014 & $\operatorname{chr} 1$ & No \\
\hline hsa-miR-138-2* & AACCCTGGTGTCGTGA & -106.3 & Cyclin D3 & 2012 & $\operatorname{chr} 16$ & Yes/no \\
\hline
\end{tabular}

Yes/no means these miRNAs have been reported differently between HBV-associated HCC and HCC with no HBV infection. miRNA/miR, microRNA; HCC, hepatocellular carcinoma; chr, chromosome; HBx, hepatitis B virus-encoded X protein; hsa, Homo sapiens; PTPRT, protein tyrosine phosphatase receptor type T; ER- $\alpha$, estrogen receptor- $\alpha$; GNAI1, guanine nucleotide-binding protein (G protein); mTOR, mechanistic target of rapamycin; TGF- $\beta$, transforming growth factor $\beta$; PPAR- $\gamma$, peroxisome proliferator-activated receptor $\gamma$; CD82, cluster of differentiation 82; NA, not available; SNAI1, snail homolog 1; CCNE1, cyclin E1.

Table III. miRNAs have never been reported in HCC, which exhibited at least a 20 -fold increase or decrease in expression of patients with HCC compared with the healthy control.

\begin{tabular}{|c|c|c|c|}
\hline miRNA name & Sequence & Fold-change & $\mathrm{Chr}$ \\
\hline hsa-miR-374a & CACTTATCAGGTTGTATTATAA & 121.4 & $\operatorname{chrX}$ \\
\hline hsa-miR-4271 & ССССАССТТТТСТТСС & 96.8 & chr3 \\
\hline hsa-miR-1471 & ACACCTGGCTCCACA & 96.3 & chr2 \\
\hline hsa-miR-188-5p & CCСТCCACCATGC & 82.1 & $\operatorname{chrX}$ \\
\hline hsa-miR-1183 & TGCCCACTCTCACCA & 81.9 & chr7 \\
\hline hsa-miR-3610 & CGGCGCCTCCTT & 64.8 & chr8 \\
\hline hsa-miR-454 & ACCCTATAAGCAATATTGCAC & 62.9 & $\operatorname{chr} 17$ \\
\hline hsa-miR-324-3p & CCAGCAGCACCTGGGG & 48.7 & $\operatorname{chr} 17$ \\
\hline hsa-miR-484 & ATCGGGAGGGGACTGA & 29.4 & $\operatorname{chr} 16$ \\
\hline hsa-miR-216b & TCACATTTGCCTGCAG & -127.6 & chr2 \\
\hline
\end{tabular}

miRNA/miR, microRNA; HCC, hepatocellular carcinoma; chr, chromosome; hsa, Homo sapiens.

the differentially expressed miRNAs, 26 miRNAs exhibited $a \geq 20$-fold increase or decrease in the plasma of patients with HCC, compared with the healthy control.

By searching the databases of PubMed, Web of Science and Google Scholar, 15 of these differentially-expressed miRNAs have been extensively reported in HCC, and 12 of them have been fully elucidated for their roles in the progression of hepatocarcinogenesis (Table II). Notably, the remaining 11 miRNAs (10 upregulated and 1 downregulated) have never been reported in liver cancer (Table III). Among them, the levels of plasma miR-3188, miR-374a, miR-4271, miR-1471, miR-188-5p, miR-1183, miR-3610, miR-454, miR-324-3p and $\mathrm{miR}-484$ were significantly increased in patients with HCC compared with the healthy control, corresponding to a fold-change of $124.5,121.4,96.8,96.3,82.1,81.9,64.8,62.9$, 48.7 and 29.4, respectively $(\mathrm{P}<0.05)$. Comparing the patients with HCC with the healthy control, only plasma miR-216b level was significantly downregulated with a fold-change of 127.6 
$(\mathrm{P}<0.01)$. The expression status of miR-216b was investigated in $150 \mathrm{HCC}$ tissues, and it was observed that miR-216b expression was downregulated in 90 patients compared with normal liver tissues. The 5-year overall survival and disease-free survival rates were significantly improved in HCC patients with increased miR-216b expression in comparison with the downregulated miR-216b expression group $(\mathrm{P}<0.001)(27)$.

\section{Discussion}

Dysregulation of miRNAs is involved in the initiation and progression of various cancers, including HCC (19). Previous studies revealed that common and specific mechanisms exist at the miRNA level during HBV-induced hepatocarcinogenesis (29), and miRNAs may function as potential biomarkers for HBV-associated HCC $(20,30)$. In addition, family history of HCC may improve the risk of $\mathrm{HCC}$ at each stage of HBV infection (7). The present study aimed to identify the plasma miRNAs that are differentially expressed in patients with HCC with familial aggregation of HCC and HBV infection.

In the present study, by virtue of microarray analysis, specific groups of miRNAs were identified, whose expression is significantly altered in the plasma of patients with HCC with familial aggregation of HCC and HBV infection. A total of 37 differently-expressed miRNAs were identified, and among them, 26 miRNAs exhibited $\geq 20$-fold-changes in the plasma of patients with HCC compared with the healthy controls. By reviewing the available literature published in previous years, among these 37 differentially expressed miRNAs, 15 miRNAs have been reported in HCC, and 12 miRNAs of them have been elaborated for the detailed molecular mechanism in the progression of HCC (Table II). The remaining 11 miRNAs have never been studied in liver cancer (Table III). Among the 11 differentially dysregulated miRNAs, the function of miR-374a, miR-188-5p, miR-1183, miR-454, miR-324-3p, miR-484, miR-3188, and miR-216b have been studied in human cancers (27,31-43); however, the exact function of miR-4271, miR-1471 and miR-3610 remains unclear.

Of these 11 miRNAs, miR-216b exhibited a 127.6-fold decrease in expression in the plasma of patients with HCC compared with that of the healthy control. Deng et al (44) firstly observed miR-216b expression in nasopharyngeal carcinoma and indicated that miR-216b was downregulated in nasopharyngeal carcinoma cell lines and specimens. miR-216b may suppress tumor growth and invasion by targeting KRAS, which performs an important role in the initiation and progression of HBV-associated HCC in mice models (45). Other studies have also revealed that miR-216b functions as a tumor-suppressor gene in colorectal and pancreatic cancers $(46,47)$. The function of miR-216b in the pathogenesis of HCC was then studied. The present results indicated that miR-216b expression was significantly lower $(\mathrm{P}<0.001)$ in tumor tissues compared with adjacent liver tissues, and its expression was associated with tumor size, HBV infection, HBV-DNA quantity and incidence of portal vein tumor thrombosis (27). Prognostic analysis revealed that the 5-year overall survival and disease-free survival rates were significantly improved in patients with HCC with increased miR-216b expression in comparison with the downregulated miR-216b expression group $(\mathrm{P}<0.001)$. In an in vitro study, miR-216b inhibited cellular proliferation, migration and invasion of HCC by directly targeting insulin-like growth factor mRNA binding protein 2, and was downregulated by HBx (27). When a miR-216b-specific inhibitor was used to block miR-216b expression in SMMC-7721 cells, in vitro and in vivo assays revealed a significant increase in proliferation, migration and invasion, compared with control SMMC-7721 cells (27).

Cai et al (31) demonstrated that miR-374a may activate Wnt/ $\beta$-catenin signaling to promote breast cancer metastasis and may perform as a therapeutic target for early metastatic breast cancer. Wnt/ $\beta$-catenin signaling has been demonstrated to perform an important role in the development and promotion of liver cancer metastasis (48), and the $\mathrm{HBx}$ protein is essential for the activation of Wnt/ $\beta$-catenin signaling in hepatoma cells (49). The expression of miR-374a was investigated in tumor tissues and adjacent normal tissues in the present study, and it was identified that no difference was observed between HCC and para-HCC tissue. The function of miR-374a in $\mathrm{HBV}$-associated $\mathrm{HCC}$ requires additional study. A previous study indicated that miR-1183 and miR-188-5p may represent specific predictors of response to chemoradiotherapy in rectal cancer (32). miR-188-5p is involved in the process of prostate cancer by regulating lysosomal protein transmembrane $4 \beta$ (LAPTM4B) (33). The downregulation of miR-188-5p is an independent prognostic factor for poor overall and biochemical recurrence-free survival rates, restoration of miR-188-5p in prostate cancer $(\mathrm{PCa})$ cells significantly suppresses proliferation, migration and invasion in vitro and inhibits tumor growth and metastasis in vivo (33); Overexpression of miR-188-5p in PC-3 cells may significantly enhance the chemosensitivity of the cells to adriamycin (33). The miR-188-5p/LAPTM4B/ phosphoinositide-3 kinase/protein kinase B regulatory network performs an important role in PCa progression and chemotherapeutic drug sensitivity (33). Recently, Fang et al (50) indicated that miR-188-5p was significantly decreased in HCC tissue, and that overexpression of miR-188-5p suppresses tumor cellular proliferation and metastasis by directly targeting fibroblastic growth factor 5 in HCC. However, in the present study, miR-188-5p exhibited an 82.1-fold increase in the plasma of patients with HCC compared with the healthy control. This demonstrated that the expression of miRNAs in the serum cannot completely reflect its expression in the tissue.

$\mathrm{Hu}$ et al (34) detected the serum miRNA profiling in patients with breast cancer. Normalized by the two endogenous control miRNAs, the authors revealed that the serum miR-324-3p expression may act as a non-invasive prediction biomarker for breast cancer. Macconi et al (35) indicated that miR-324-3p promotes renal fibrosis by targeting prolyl endopeptidase. In addition, a previous study revealed that miR-324-3p targets the promoter of RelA, commonly known as $\mathrm{p} 65$, a subunit of nuclear factor-kB, and significantly induced the endogenous RelA mRNA and protein expression in PC12 cells (36). The present results also demonstrated that miR-324-3p exhibited a 48.7-fold increase in the plasma of patients with HCC compared with the control, which may be considered as a biomarker in HCC.

miR-484 has been identified to be increased in the serum of patients with breast and pancreatic cancer (37). The present results revealed that miR-484 exhibited a 29.7 -fold-change in expression in patients with HCC compared with the 
healthy control. These findings indicated that miR-484 may be produced as a result of processes common to these three cancers. The study by Wang et al (38) also indicated that miR-484 may function as an oncogene, suppress translation of mitochondrial fission protein (Fis1) and inhibit Fis1-mediated fission and apoptosis.

Previous studies have demonstrated that miR-454 acts as an oncogene or tumor suppressor in cancer (39-41). miR-454 has been reported to be decreased in tissue of patients with esophageal cancer compared with normal tissue, which may perform as novel molecular markers of esophageal cancer (39). Niu et al (40) demonstrated that miR-454 expression was downregulated in osteosarcoma tissues, acting as a tumor suppressor gene in osteosarcoma. The miR-454 expression was increased in colorectal cancer (CRC) tissues and CRC cells. Overexpression of miR-454 promoted the proliferation and anchorage-independent growth of CRC cells and its oncogenic effect was mediated chiefly through direct suppression of cylindromatosis expression (41). In the present study, miR-454 exhibited a 62.9-fold increase in the plasma of patients with $\mathrm{HCC}$ in comparison with the healthy control, demonstrating that miR-454 may function as an oncogene. A total of 110 pairs of HCC tissues and para-cancer tissues were compared, and the results revealed that miR-454 was significantly increased in 83 HCC tissues compared with para-cancer tissues. The 5-year overall survival and disease-free survival rates were significantly improved in patients with low expression of miR-454 (data unpublished). Until recently, Yu et al (42) indicated that miR-454 expression was upregulated in HCC cell lines and tissues. Knockdown of miR-454 inhibited HCC cellular proliferation, invasion and epithelial mesenchymal transition (EMT), whereas overexpression of miR-454 promoted HCC cellular proliferation and invasion and EMT, which was consistent with the present results. miR-3188 directly targets mTOR to stimulate its own expression, and participates in FOXO1-mediated repression of cell growth, tumorigenesis and nasopharyngeal carcinoma chemotherapy resistance (43). However, miR-3188 has never been studied in HCC, and the aim of the present study was to investigate the function of miR-3188 in the pathogenesis of HCC.

In conclusion, the present study (in a small sample size) identified a list of differentially-expressed miRNA candidates in the plasma of patients with familial HCC with HBV infection compared with the healthy control. A total of 11 of these miRNAs have not previously been reported in the molecular pathogenesis of hepatocarcinogenesis. These differentially expressed miRNAs in the plasma of patients with HCC with familial aggregation of $\mathrm{HCC}$ and $\mathrm{HBV}$ infection may lay the foundation for additional studies on the role of miRNAs in the pathogenesis of HCC, and provide the basal work for future study of the molecular mechanisms of HCC. Additional studies are necessary in order to understand the regulatory mechanisms of these miRNAs in the process of hepatocarcinogenesis.

\section{References}

1. Zhang EL, Liang BY, Chen XP and Huang ZY: Severity of liver cirrhosis: A key role in the selection of surgical modality for Child-Pugh A hepatocellular carcinoma. World J Surg Oncol 13: $148,2015$.
2. Kew MC: Epidemiology of chronic hepatitis B virus infection, hepatocellular carcinoma, and hepatitis B virus-induced hepatocellular carcinoma. Pathol Biol (Paris) 58: 273-277, 2010.

3. Yang HI, Lu SN, Liaw YF, You SL, Sun CA, Wang LY, Hsiao CK, Chen PJ, Chen DS and Chen CJ; Taiwan Community-Based Cancer Screening Project Group: Hepatitis B e antigen and the risk of hepatocellular carcinoma. N Engl J Med 347: 168-174, 2002.

4. Lok AS: Prevention of hepatitis B virus-related hepatocellular carcinoma. Gastroenterology 127 (Suppl 1): S303-S309, 2004.

5. Mair RD, Valenzuela A, Ha NB, Ayoub WS, Daugherty T, Lutchman GA, Garcia G, Ahmed A and Nguyen MH: Incidence of hepatocellular carcinoma among US patients with cirrhosis of viral or nonviral etiologies. Clin Gastroenterol Hepatol 10: 1412-1417, 2012.

6. Yu MW, Chang HC, Liaw YF, Lin SM, Lee SD, Liu CJ, Chen PJ, Hsiao TJ, Lee PH and Chen CJ: Familial risk of hepatocellular carcinoma among chronic hepatitis B carriers and their relatives. J Natl Cancer Inst 92: 1159-1164, 2000.

7. Loomba R, Liu J, Yang HI, Lee MH, Lu SN, Wang LY, Iloeje UH, You SL, Brenner D and Chen CJ; REVEAL-HBV Study Group: Synergistic effects of family history of hepatocellular carcinoma and hepatitis B virus infection on risk for incident hepatocellular carcinoma. Clin Gastroenterol Hepatol 11: 1636-1645.e1-3, 2013.

8. Turati F, Edefonti V, Talamini R, Ferraroni M, Malvezzi M, Bravi F, Franceschi S, Montella M, Polesel J, Zucchetto A, et al: Family history of liver cancer and hepatocellular carcinoma. Hepatology 55: 1416-1425, 2012.

9. Xie KL, Zhang YG, Liu J,Zeng Y and Wu H: MicroRNAs associated with HBV infection and HBV-related HCC. Theranostics 4: 1176-1192, 2014.

10. Zhao Z, Hu Y, Shen X, Lao Y, Zhang L, Qiu X, Hu J, Gong P, Cui $\mathrm{H}, \mathrm{Lu} \mathrm{S}$, et al: HBx represses RIZ1 expression by DNA methyltransferase 1 involvement in decreased miR-152 in hepatocellular carcinoma. Oncol Rep 37: 2811-2818, 2017.

11. Wu Y, Zhang J, Zhang H and Zhai Y: Hepatitis B virus X protein mediates yes-associated protein 1 upregulation in hepatocellular carcinoma. Oncol Lett 12: 1971-1974, 2016.

12. Xu C, Zhou W, Wang Y and Qiao L: Hepatitis B virus-induced hepatocellular carcinoma. Cancer Lett 345: 216-222, 2014.

13. Huang $\mathrm{S}$ and He $\mathrm{X}$ : The role of microR NAs in liver cancer progression. Br J Cancer 104: 235-240, 2011.

14. Valencia-Sanchez MA, Liu J, Hannon GJ and Parker R: Control of translation and mRNA degradation by miRNAs and siRNAs. Genes Dev 20: 515-524, 2006.

15. Braconi C, Huang $\mathrm{N}$ and Patel T: MicroRNA-dependent regulation of DNA methyltransferase-1 and tumor suppressor gene expression by interleukin- 6 in human malignant cholangiocytes. Hepatology 51: 881-890, 2010.

16. Wei X, Xiang T, Ren G, Tan C, Liu R, Xu X and Wu Z: miR-101 is down-regulated by the hepatitis $\mathrm{B}$ virus $\mathrm{x}$ protein and induces aberrant DNA methylation by targeting DNA methyltransferase 3A. Cell Signal 25: 439-446, 2013.

17. Wei X, Tan C, Tang C, Ren G, Xiang T, Qiu Z, Liu R and Wu Z: Epigenetic repression of miR-132 expression by the hepatitis $B$ virus $\mathrm{x}$ protein in hepatitis $\mathrm{B}$ virus-related hepatocellular carcinoma. Cell Signal 25: 1037-1043, 2013.

18. Dong Y and Wang A: Aberrant DNA methylation in hepatocellular carcinoma tumor suppression (Review). Oncol Lett 8: 963-968, 2014.

19. Liu WH, Yeh SH and Chen PJ: Role of microRNAs in hepatitis B virus replication and pathogenesis. Biochim Biophys Acta 1809: 678-685, 2011.

20. Zhou J, Yu L, Gao X, Hu J, Wang J, Dai Z, Wang JF, Zhang Z, Lu S, Huang X, et al: Plasma microRNA panel to diagnose hepatitis B virus-related hepatocellular carcinoma. J Clin Oncol 29: 4781-4788, 2011

21. Fu Y, Wei X, Tang C, Li J, Liu R, Shen A and Wu Z: Circulating microRNA-101 as a potential biomarker for hepatitis B virus-related hepatocellular carcinoma. Oncol Lett 6: 1811-1815, 2013.

22. Katayama Y, Maeda M, Miyaguchi K, Nemoto S, Yasen M, Tanaka S, Mizushima H, Fukuoka Y, Arii S and Tanaka H: Identification of pathogenesis-related microRNAs in hepatocellular carcinoma by expression profiling. Oncol Lett 4: 817-823, 2012.

23. Wang Y, Lu Y, Toh ST, Sung WK, Tan P, Chow P, Chung AY, Jooi LL and Lee CG: Lethal-7 is down-regulated by the hepatitis $\mathrm{B}$ virus $\mathrm{x}$ protein and targets signal transducer and activator of transcription 3. J Hepatol 53: 57-66, 2010. 
24. Kong G, Zhang J, Zhang S, Shan C, Ye L and Zhang X: Upregulated microRNA-29a by hepatitis B virus $X$ protein enhances hepatoma cell migration by targeting PTEN in cell culture model. PLoS One 6: e19518, 2011.

25. Wu G, Yu F, Xiao Z, Xu K, Xu J, Tang W, Wang J and Song E: Hepatitis $B$ virus $X$ protein downregulates expression of the miR-16 family in malignant hepatocytes in vitro. Br J Cancer 105 146-153, 2011

26. Xu X, Fan Z, Kang L, Han J, Jiang C, Zheng X, Zhu Z, Jiao H, Lin J, Jiang K, et al: Hepatitis B virus $X$ protein represses miRNA-148a to enhance tumorigenesis. J Clin Invest 123 630-645, 2013

27. Liu FY, Zhou SJ, Deng YL, Zhang ZY, Zhang EL, Wu ZB, Huang ZY and Chen XP: MiR-216b is involved in pathogenesis and progression of hepatocellular carcinoma through HBx-miR-216b-IGF2BP2 signaling pathway. Cell Death Dis 6: e1670, 2015.

28. Hassan MM, Spitz MR, Thomas MB, Curley SA, Patt YZ, Vauthey JN, Glover KY, Kaseb A, Lozano RD, El-Deeb AS, et al: The association of family history of liver cancer with hepatocellular carcinoma: A case-control study in the United States. J Hepatol 50: 334-341, 2009.

29. Zhang ZZ, Liu X, Wang DQ, Teng MK, Niu LW, Huang AL and Liang Z: Hepatitis B virus and hepatocellular carcinoma at the miRNA level. World J Gastroenterol 17: 3353-3358, 2011.

30. Tan Y, Ge G, Pan T, Wen D, Chen L, Yu X, Zhou X and Gan J: A serum microRNA panel as potential biomarkers for hepatocellular carcinoma related with hepatitis B virus. PLoS One 9: e107986, 2014

31. Cai J, Guan H, Fang L, Yang Y, Zhu X, Yuan J, Wu J and Li M MicroRNA-374a activates Wnt/ $\beta$-catenin signaling to promote breast cancer metastasis. J Clin Invest 123: 566-579, 2013.

32. Della Vittoria Scarpati G, Falcetta F, Carlomagno C, Ubezio P, Marchini S, De Stefano A, Singh VK, D'Incalci M, De Placido S and Pepe S: A specific miRNA signature correlates with complete pathological response to neoadjuvant chemoradiotherapy in locally advanced rectal cancer. Int J Radiat Oncol Biol Phys 83: 1113-1119, 2012.

33. Zhang H, Qi S, Zhang T, Wang A, Liu R, Guo J, Wang Y and $\mathrm{Xu}$ Y: miR-188-5p inhibits tumour growth and metastasis in prostate cancer by repressing LAPTM4B expression. Oncotarget 6: 6092-6104, 2015.

34. Hu Z, Dong J, Wang LE, Ma H, Liu J, Zhao Y, Tang J, Chen X, Dai J, Wei Q, et al: Serum microRNA profiling and breast cancer risk: The use of miR-484/191 as endogenous controls. Carcinogenesis 33: 828-834, 2012.

35. Macconi D, Tomasoni S, Romagnani P, Trionfini P, Sangalli F, Mazzinghi B, Rizzo P, Lazzeri E, Abbate M, Remuzzi G and Benigni A: MicroRNA-324-3p promotes renal fibrosis and is a target of ACE inhibition. J Am Soc Nephrol 23: 1496-1505, 2012

36. Dharap A, Pokrzywa C, Murali S, Pandi G and Vemuganti R: MicroRNA miR-324-3p induces promoter-mediated expression of RelA gene. PLoS One 8: e79467, 2013.
37. Zearo S, Kim E, Zhu Y, Zhao JT, Sidhu SB, Robinson BG and Soon PSh: MicroRNA-484 is more highly expressed in serum of early breast cancer patients compared to healthy volunteers. BMC Cancer 14: 200, 2014

38. Wang K, Long B, Jiao JQ, Wang JX, Liu JP, Li Q and Li PF: miR-484 regulates mitochondrial network through targeting Fis1. Nat Commun 3: 781, 2012.

39. Liu SG, Qin XG, Zhao BS, Qi B, Yao WJ, Wang TY, Li HC and $\mathrm{Wu} \mathrm{XN}$ : Differential expression of miRNAs in esophageal cancer tissue. Oncol Lett 5: 1639-1642, 2013.

40. Niu G, Li B, Sun J and Sun L: miR-454 is down-regulated in osteosarcomas and suppresses cell proliferation and invasion by directly targeting c-Met. Cell Prolif 48: 348-355, 2015.

41. Liu L, Nie J, Chen L, Dong G, Du X, Wu X, Tang Y and Han W: The oncogenic role of microRNA-130a/301a/454 in human colorectal cancer via targeting Smad4 expression. PLoS One 8: e55532, 2013

42. Yu L, Gong X, Sun L, Yao H, Lu B and Zhu L: miR-454 functions as an oncogene by inhibiting CHD5 in hepatocellular carcinoma. Oncotarget 6: 39225-39234, 2015.

43. Zhao M, Luo R, Liu Y, Gao L, Fu Z, Fu Q, Luo X, Chen Y, Deng X, Liang Z, et al: miR-3188 regulates nasopharyngeal carcinoma proliferation and chemosensitivity through a FOXO1-modulated positive feedback loop with mTOR-p-PI3K/AKT-c-JUN. Nat Commun 7: 11309, 2016.

44. Deng M, Tang H, Zhou Y, Zhou M, Xiong W, Zheng Y, Ye Q, Zeng X, Liao Q, Guo X, et al: miR-216b suppresses tumor growth and invasion by targeting KRAS in nasopharyngeal carcinoma. J Cell Sci 124: 2997-3005, 2011.

45. Ye H, Zhang C, Wang BJ, Tan XH, Zhang WP, Teng Y and Yang X: Synergistic function of Kras mutation and $\mathrm{HBX}$ in initiation and progression of hepatocellular carcinoma in mice. Oncogene 33: 5133-5138, 2014.

46. Kim SY, Lee YH and Bae YS: MiR-186, miR-216b, miR-337-3p, and miR-760 cooperatively induce cellular senescence by targeting $\alpha$ subunit of protein kinase CKII in human colorectal cancer cells. Biochem Biophys Res Commun 429: 173-179, 2012.

47. Ali S, Banerjee S, Logna F, Bao B, Philip PA, Korc M and Sarkar FH: Inactivation of Ink4a/Arf leads to deregulated expression of miRNAs in K-Ras transgenic mouse model of pancreatic cancer. J Cell Physiol 227: 3373-3380, 2012.

48. Anson M, Crain-Denoyelle AM, Baud V, Chereau F, Gougelet A, Terris B, Yamagoe S, Colnot S, Viguier M, Perret C and Couty JP: Oncogenic $\beta$-catenin triggers an inflammatory response that determines the aggressiveness of hepatocellular carcinoma in mice. J Clin Invest 122: 586-599, 2012.

49. Cha MY, Kim CM, Park YM and Ryu WS: Hepatitis B virus $\mathrm{X}$ protein is essential for the activation of Wnt/beta-catenin signaling in hepatoma cells. Hepatology 39: 1683-1693, 2004

50. Fang F, Chang RM, Yu L, Lei X, Xiao S, Yang H and Yang LY: MicroRNA-188-5p suppresses tumor cell proliferation and metastasis by directly targeting FGF5 in hepatocellular carcinoma. J Hepatol 63: 874-885, 2015. 